\title{
The Diagnosis and Treatment of Functional Dyspepsia
}

\author{
Ahmed Madisch, Viola Andresen, Paul Enck, Joachim Labenz, Thomas Frieling, \\ Michael Schemann
}

Department of Gastroenterology, Interventional Endoscopy,4 Diabetology, and Acute Geriatrics KRH Hospital Siloah, Hanover: Prof.

Ahmed Madisch

Department of

Medicine, Israelite Hospital, Hamburg: PD Dr. Viola Andresen

Internal Medicine Vl: Psychosomatic Medicine and Psychotherapy, University Hospital Tübingen, Tübingen:

Prof. Paul Enck

Department of Medicine, Diakonie Hospital Jung-Stilling, Siegen: Prof. Joachim Labenz

Department of Gastroenterology, Helios Hospital Krefeld, Krefeld: Prof. Thomas Frieling

Chair of Human Biology, TU Munich, Freising: Prof. Michael Schemann

\section{Summary \\ Background: Functional dyspepsia (FD) is one of the more common functional disorders, with a prevalence of $10-20 \%$. It affects the gastrointestinal tract.

\begin{abstract}
Methods: This article is based on publications retrieved by a selective search of PubMed, with special attention to controlled trials, guidelines, and reviews.
\end{abstract}

Results: Typical dyspeptic symptoms in functional dyspepsia include epigastric pain, sensations of pressure and fullness, nausea, and early subjective satiety. The etiology of the disorder is heterogeneous and multifactorial. Contributory causes include motility disturbances, visceral hypersensitivity, elevated mucosal permeability, and disturbances of the autonomic and enteric nervous system. There is as yet no causally directed treatment for functional dyspepsia. Its treatment should begin with intensive patient education regarding the benign nature of the disorder and with the establishment of a therapeutic pact for long-term care. Given the absence of a causally directed treatment, drugs to treat functional dyspepsia should be given for no more than 8-12 weeks. Proton-pump inhibitors, phytotherapeutic drugs, and Helicobacter pylori eradication are evidence-based interventions. For intractable cases, tricyclic antidepressants and psychotherapy are further effective treatment options.

Conclusion: The impaired quality of life of patients with functional dyspepsia implies the need for definitive establishment of the diagnosis, followed by symptom-oriented treatment for the duration of the symptomatic interval.

\section{Cite this as:}

Madisch A, Andresen V, Enck P, Labenz J, Frieling T, Schemann M: The diagnosis and treatment of functional dyspepsia. Dtsch Arztebl Int 2018; 115: 222-32. DOI: 10.3238/arztebl.2018.0222

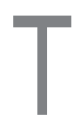
he term dyspepsia (Greek "dys" [bad], "pepsis" [digestion]) is used for a spectrum of symptoms localized by the patient to the epigastric region (between the navel and the xiphoid process) and the flanks. These symptoms include epigastric pain and burning (60 to $70 \%$ ), feeling bloated after a meal $(80 \%)$, early satiation (60 to $70 \%)$, distension in the epigastric region $(80 \%)$, Nausea $(60 \%)$, and vomiting (40\%). The symptoms of dyspepsia may be acute, e.g., in gastroenteritis, or chronic. In the latter case, underlying organic (e.g., ulcer, reflux, pancreatic disease, heart and muscle disease) or functional factors may be responsible.

\section{Definition}

The term dyspepsia (Greek "dys" [bad], "pepsis" [digestion]) is used for a spectrum of symptoms localized by the patient to the epigastric region (between the navel and the xiphoid process) and the flanks.
On diagnostic work-up, 20 to $30 \%$ of patients with dyspepsia are found to have diseases that account for their symptoms $(1,2)$. Functional dyspepsia (synonym: irritable stomach syndrome) is present whenever routine diagnostic investigations, including endoscopy, do not identify any causal structural or biochemical abnormalities (1-6). Findings such as gallstones, hiatus hernia, gastric erosions, or "gastritis" do not necessarily explain the symptoms and thus do not contradict a diagnosis of functional dyspepsia.

Against the background of our professional experience, we carried out a selective search of the literature in PubMed. The inclusion criteria were as follows:

\section{Functional dyspepsia}

Functional dyspepsia (synonym: irritable stomach syndrome) is present whenever routine diagnostic investigations, including endoscopy, do not identify any causal structural or biochemical abnormalities. 
- Full text in English or German

- Study types: "clinical trial," "randomized controlled trial," "meta-analysis," "systematic review," "practice guideline," "guideline," "review."

\section{Learning goals}

After finishing this article, the reader should:

- Know how functional dyspepsia is defined according to the current guidelines

- Be familiar with the criteria according to which functional dyspepsia can manifest clinically

- Be able to carry out the general measures of primary care and have gained knowledge of the medical treatment options for which there is evidence of efficacy against functional dyspepsia.

\section{Definition of functional dyspepsia}

According to the recently revised Rome IV criteria (1), functional dyspepsia is defined by:

- Persistent or recurring dyspepsia for more than 3 months within the past 6 months

- No demonstration of a possible organic cause of the symptoms on endoscopy

- No sign that the dyspepsia is relieved only by defecation or of an association with stool irregularities.

This last criterion was introduced to rule out irritable bowel syndrome (IBS) as a possible cause of the symptoms, although around $30 \%$ of patients with functional dyspepsia also have IBS.

The current Rome IV criteria (1) divide functional dyspepsia into two subgroups according to the cardinal symptoms (Figure 1):

- Epigastric pain syndrome (EPS)-predominant epigastric pain or burning

- Postprandial distress syndrome (PDS) - feeling of fullness and early satiation.

\section{Epidemiology and natural disease course}

Dyspeptic symptoms are common and cause considerable direct (visits to the doctor, medications, etc.) and particularly indirect costs (time off work) (3). Some 18 to $20 \%$ of Germans complain of bloating, flatulence, heartburn, and diarrhea (6). In the prospective Domestic International Gastro Enterology Surveillance Study (DIGEST) a survey of over 5500 persons showed that around one third of the normal persons interviewed reported dyspeptic symptoms, including acute dyspepsia in $6.5 \%$ and chronic dyspepsia in $22.5 \%$ of cases $(7$, 8). Only in 10 to $25 \%$ is the social impact of their symptoms great enough for them to consult a physician (3). As shown by an Anglo-American study, however, this group causes costs amounting to several billion EUR each year. These costs are either direct, caused by demands on healthcare services, or indirect, through time off work and early retirement $(7,9)$. The disease displays a periodic course, phases of slight or no symptoms alternating with periods of intensive complaints. Only $20 \%$ of patients with functional dyspepsia ever become free of symptoms in the long term $(1,2,5,6)$.

\section{Pathogenesis of functional dyspepsia}

The causes of functional dyspepsia are heterogeneous and multifactorial. In recent decades numerous systematic pathophysiological studies comparing functional dyspepsia patients with healthy volunteers have shown that functional dyspepsia is an organic disorder, even though the pathophysiologically relevant factors discussed in the further course of this article currently cannot be detected by routine clinical work-up $(5,10-13)$. This includes motility disorders, sensorimotor dysfunction connected with hypersensitivity to mechanical and chemical stimuli, immune activation, elevated mucosal permeability in the proximal small intestine, and disorders of the autonomic and enteric nervous systems (Table 1) (12). As is the case for many diseases, the causal link between the development of symptoms and organic disorders has not yet been clarified. It is also important that the disorders do not occur in all patients and that the changes in motility and sensitivity are not restricted to the stomach. Moreover, no studies have been carried out to establish which factors occur together or in isolation from one another.

Patients with functional dyspepsia have disordered accommodation of the proximal stomach both after balloon dilatation of the stomach and after a meal (14). This is shown in both cases by inadequate relaxation of the fundus. The result is a disproportional distribution of the stomach contents, with a greater volume in the antrum than in the fundus (15). The extent of antral expansion has been found to be associated with increasing severity of symptoms (total score from the symptoms of early satiation, epigastric pain, bloating, and nausea or vomiting) $(14,15)$. Furthermore, patients with functional dyspepsia also exhibit disordered fundus relaxation after expansion of the duodenum (16).

Both with an empty stomach and after a meal, patients with functional dyspepsia suffer from visceral hypersensitivity when the gastric fundus is expanded $(17,18)$. The proportion of patients found to have this hypersensitivity depends on the diagnostic criteria and on whether hypersensitivity is defined as abnormal pain projection, allodynia, and/or hyperalgesia.
Functional dyspepsia is divided into two subgroups according to the cardinal symptoms:

- Epigastric pain syndrome (EPS)-predominant epigastric pain or burning

- Postprandial distress syndrome (PDS)_feeling of fullness and early satiation.

\section{Epidemiology}

Dyspeptic symptoms are common and cause considerable direct and particularly indirect costs (3). Some 18 to $20 \%$ of Germans complain of bloating, flatulence, heartburn, and diarrhea. 
FIGURE 1

Postprandial
dyspeptic
symptoms
(PDS)

- Bloating
- Early satiation
- Nausea
- Retching
- Vomiting
- Loss of appetite

Definition of functional dyspepsia according to the Rome IV criteria (1)

In any case the hypersensitivity correlates with the severity of the symptoms (19). Even patients with normal fundus accommodation may react hypersensitively to expansion of the stomach (20), and some patients with functional dyspepsia also react hypersensitively to expansion of the duodenum, jejunum, or rectum (21). This finding points to generalized rather than local visceral sensitization of the efferent or afferent enteric nerves or of the sensory nerves connecting the gut with the central nervous system (gut-brain axis). The hypersensitivity following stomach expansion is ameliorated by inhibition of cholinergic tone but not by active muscle relaxation by means of the NO donor nitroglycerin (22). This shows the predominant role of the cholinergic enteric innervation in the origin of hypersensitivity.

Symptoms of functional dyspepsia occur after infusion of acid into the duodenum (23) and probably result from sensitized $\mathrm{pH}$ sensors or insufficient removal of the acid due to impaired motor function of the proximal duodenum (24). This is in accordance with the elevated sensitivity to capsaicin (25). Capsaicin is a TRPV1 agonist (transient receptor potential cation channel subfamily $\mathrm{V}$ member 1 ) that is stimulated by, among other factors, decreased $\mathrm{pH}$.

The presence of fat in the duodenum triggers the symptoms of functional dyspepsia due to direct neural action, increased sensitivity of enteroendocrine cells, systemic or local elevation of cholecystokinin concentration, and/or increased sensitivity of the cholecystokinin-A receptors (26).

\section{The role of mental factors in the pathogenesis}

Although functional dyspepsia differs in both symptoms and clinical signs from IBS (27), the other frequently encountered functional disorder in the realm of gastroenterology, with regard to the significance of mental factors in pathogenesis, diagnosis, and treatment there are more similarities than differences between the two diseases. On psychometric test scales, patients with functional dyspepsia score higher than those without gastrointestinal symptoms for depression, anxiety, and somatization, which are more strongly associated with decreased quality of life than are the clinical symptoms themselves (13). This points to "pathological" central processing of visceral stimuli, e.g., increased vigilance against specific sensations from the gastrointestinal tract. This increased vigilance may arise in the context of postinfectious sensitization. The frequent association of functional dyspepsia with other intestinal and extraintestinal diseases also indicates a "somatization disorder" similar to IBS. These possible biopsychosocial factors are shown as a separate category in Table 1 .

\section{Confirmation of functional dyspepsia}

Confirmation of the diagnosis of functional dyspepsia rests on:

- The typical symptoms and the patient's history

- The exclusion of other diseases of the upper gastrointestinal tract and upper abdominal organs that may present with similar dyspeptic symptoms $(1,4,6)$.

The typical nongastrointestinal accompanying symptoms are general vegetative symptoms such as increased sweating, headache, sleep disorders, muscular tension, functional cardiac symptoms, and irritable bladder. On questioning, the patient typically reports a long history of complaints, variable symptoms with no clear progression, diffuse pain of variable location, absence of unintentional weight loss, and dependence of the symptoms on stress.

The only instrumental diagnostic examinations thought to be sufficiently accurate are esophagogastroduodenoscopy including investigation for Helicobacter pylori and abdominal ultrasonography, accompanied in the presence of additional symptoms of IBS by endoscopic inspection of the colon. These investigations are indicated in cases where the medical history and symptoms are typical and the preliminary laboratory tests such as blood count, electrolytes, and hepatic and renal function, as well as erythrocyte sedimentation rate or CRP and, if applicable, peripheral thyroid parameters are in the normal range (Figure 2) $(1,28)$.

In patients who fail to respond to treatment, specialized diagnostic procedures should be carried

\section{Mental factors}

Patients with functional dyspepsia score higher than those without gastrointestinal symptoms for depression, anxiety, and somatization, which are more strongly associated with decreased quality of life than are the clinical symptoms themselves.

\section{Confirmation of the diagnosis rests on:}

- The typical symptoms and the patient's history

- The exclusion of other diseases of the upper gastrointestinal tract and upper abdominal organs that may present with similar dyspeptic symptoms. 
Functional disorders and their pathophysiological substrates in functional dyspepsia*

\begin{tabular}{|c|c|}
\hline & Pathophysiologically relevant factors \\
\hline Motility disorders & $\begin{array}{l}\text { - Impaired volume accommodation of the fundus } \\
\text { - Disproportionate volume distribution in the stomach (too much in the antrum, too little in the } \\
\text { fundus) } \\
\text { - Low volume uptake in drinking test } \\
\text { - Antral hypomotility and } \downarrow \text { antral migratory motor complexes (phase III of interdigestive } \\
\text { motoricity) } \\
\text { - Uncoordinated antroduodenal motility } \\
\text { - Increased postprandial duodenal motility } \\
\text { - Insufficient inhibitory components of the peristaltic reflex in the small intestine }\end{array}$ \\
\hline Sensorimotor disorders & $\begin{array}{l}\text { - Reduced excitability of enteric nerves in the duodenum } \\
\text { - Gliosis in the duodenal submucous plexus } \\
\text { - } \downarrow \text { Parasympathetic tonus } \\
\text { - } \uparrow \text { Acid sensitivity in the duodenum } \\
\text { - } \uparrow \text { Fat sensitivity in the duodenum associated with } \uparrow \text { CCK sensitivity } \\
\text { - } \uparrow \text { Starved and postprandial CCK concentration but } \downarrow P Y Y \text { concentration } \\
\text { - } \downarrow \text { CgA+ enteroendocrine cells in the duodenum }\end{array}$ \\
\hline Visceral hypersensitivity & $\begin{array}{l}\text { - } \uparrow \text { Sensitivity after stomach expansion (on an empty stomach and after a meal) } \\
\text { - } \text { Sensitivity after duodenal, jejunal, and rectal expansion }\end{array}$ \\
\hline $\begin{array}{l}\text { Postinfectious plasticity of the } \\
\text { duodenum }\end{array}$ & $\begin{array}{l}-\uparrow \mathrm{CD} 8+\text { cytotoxic T cells CD } 68+\text { and CCR2+ macrophages } \\
-\downarrow \mathrm{CD} 4+\text { T-helper cells in the duodenum }\end{array}$ \\
\hline Immune activation & $\begin{array}{l}\text { - } \uparrow \text { GDNF, eosinophilic granulocytes and macrophages in duodenal mucosal biopsy samples } \\
\text { } \uparrow \text { Degranulation of the eosinophilic granulocytes in the duodenum } \\
\text { TH2-mediated response in the duodenum } \\
\text { - } \uparrow \text { GDNF and NGF expression in the H. pylori-positive gastric mucosa }\end{array}$ \\
\hline Dysfunctional intestinal barrier & - $\uparrow$ Permeability in the proximal small intestine \\
\hline Genetic predisposition & $\begin{array}{l}\text { - } \uparrow \text { GNß3-TT genotype (increased signal transduction between receptor and target protein) } \\
\text { - } \downarrow \text { CCK-A receptor CC genotype }\end{array}$ \\
\hline Biopsychosocial factors & $\begin{array}{l}\text { - } \uparrow \text { Anxiety, depression, somatization, neuroticism } \\
\text { - } \uparrow \text { Experience of abuse, stressful life events } \\
\text { - } \downarrow \text { Functional connectivity of brain regions }\end{array}$ \\
\hline Altered microbiota & $\begin{array}{l}\text { - } \uparrow \text { Prevotella } \\
\text { - Helicobacter pylori }\end{array}$ \\
\hline
\end{tabular}

CCK, Cholecystokinin; CgA, chromogranin A; GDNF, glial cell line-derived neurotrophic factor; GNß3, G-protein $\beta$ polypeptide-3; NGF, nerve growth factor; PYY, peptide YY

* Modified from $(10,12)$

out on an individual basis. In the presence of accompanying symptoms of reflux, 24-h monitoring of esophageal $\mathrm{pH} /$ impedance may be helpful (29). ${ }^{13} \mathrm{C}$ breath tests and gastric emptying scintigraphy may detect an underlying gastric emptying disorder or gastroparesis.

In the case of accompanying severe flatulence, further breath tests for carbohydrate intolerance and abnormal bacterial colonization may be useful. Patients whose symptoms do not respond to treatment should be screened for mental disorders such as anxiety, depression, and stress (13, 30-32).

\section{Instrumental diagnostic examinations}

Only esophagogastroduodenoscopy including investigation for Helicobacter pylori and abdominal ultrasonography, accompanied in the presence of additional symptoms of IBS by endoscopic inspection of the colon, are thought to be sufficiently accurate.
The diagnostic work-up often reveals findings that are attributed endoscopically, and then also histologically, to gastritis. Patients who actually have functional dyspepsia are frequently assigned the diagnosis "gastritis" on the basis of the endoscopic and histological results. The term "gastritis" as clinical diagnosis should thus be avoided in favor of functional dyspepsia, particularly because the endoscopic and histological finding of gastritis does not correspond to the patients' symptoms $(13,33)$.

Appropriate diagnostic investigation and confirmation should not be followed by repeated examination. 
Diagnostic

procedure in

patients with

dyspeptic symptoms

$(1,28)$.

H.p., Helicobacter

pylori;

EGD, esophagogas-

troduodenoscopy
FIGURE 2

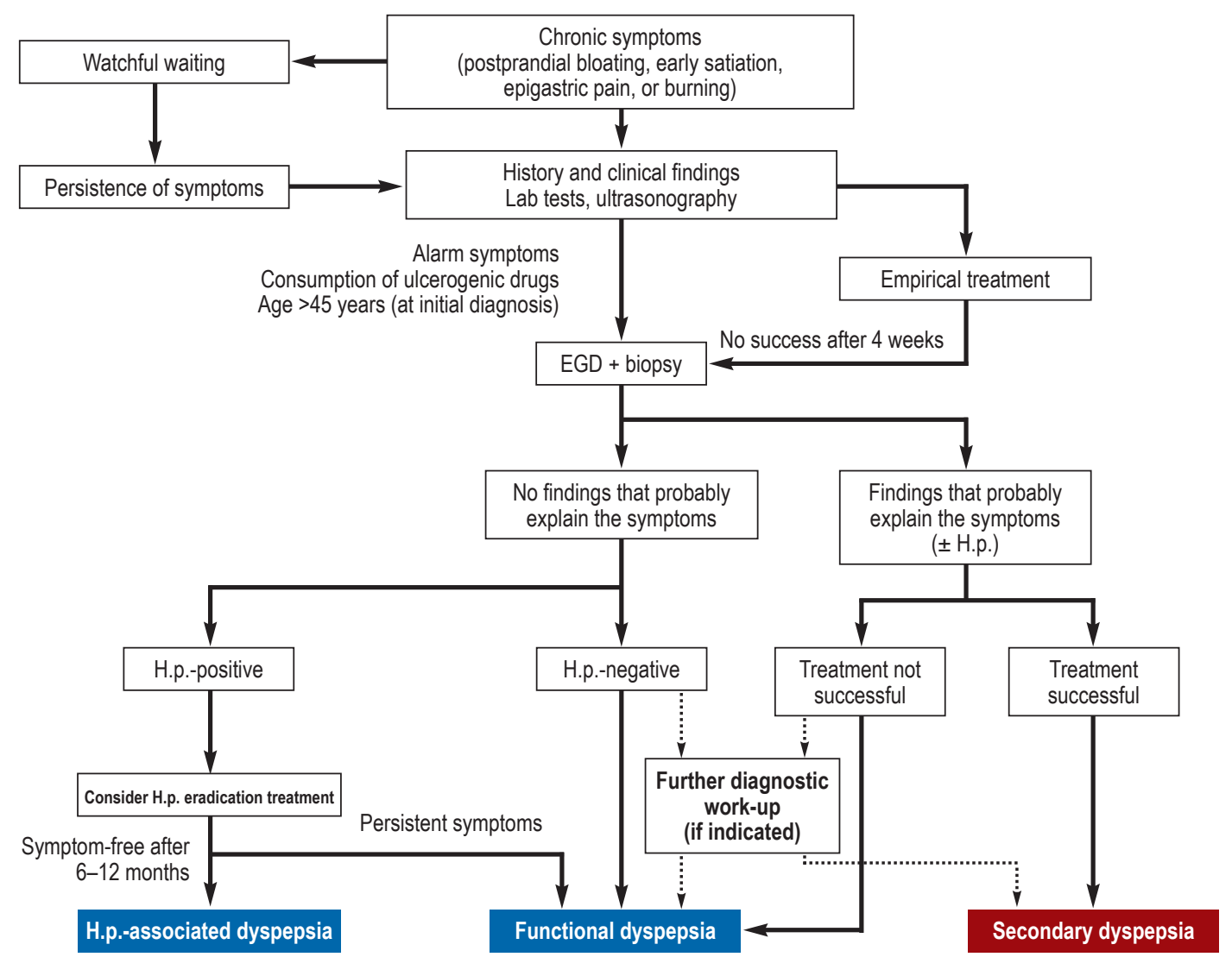

Only if the symptoms change or in refractory cases is re-evaluation or an extended work-up required.

\section{Treatment options for functional dyspepsia General measures}

When functional dyspepsia has been confirmed, one of the first treatment measures is exhaustive explanation of the diagnosis and its consequences to the patient $(28,34)$. It is crucial to the success of treatment to explain the essence of the diagnosis to the patient in simple, comprehensible terms, stressing that functional dyspepsia is a benign but organic disease that may arise from various underlying disorders. At the same time, the patient must be informed about the treatment options. The following nonmedicinal general measures are currently recommended, although

\section{The term "gastritis"}

The diagnostic work-up often reveals findings that are attributed to gastritis. Patients who actually have functional dyspepsia are frequently given the diagnosis "gastritis"on the basis of the endoscopic and histological results. their efficacy has not been confirmed in controlled trials (34):

- Clear explanation of the diagnosis with interpretation of the findings (reassurance that the symptoms are not caused by cancer)

- Explanation of the nature and cause(s) of the symptoms

- Conflict resolution in the psychosocial domain

- Encouraging the patient to take responsibility

- Relaxation exercises

- Treatment alliance for long-term care

- Psychotherapeutic options.

Diet plays only a minor role in functional dyspepsia. The patient should note what foods he/ she does not tolerate and avoid them. To this end, it may be useful to keep a symptom diary, particularly 
in the diagnostic phase. Regular meals, avoidance of excessively large meals, thorough mastication, and not rushing meals are general recommendations that may also be helpful in functional dyspepsia.

\section{Medicinal treatment}

Medicinal treatment is primarily recommended as a supportive measure in the symptomatic intervals (1, $4-6,10,13)$. In the absence of causal therapy, the duration of treatment is therefore limited (e.g., a period of 8-12 weeks) and is always oriented on the principal symptoms, particularly since the placebo success rate can be very high, up to $60 \%$.

In this context, it is crucial for physician and patient to agree on realistic treatment goals, with the emphasis on alleviation of symptoms by the systematic application of various treatment options.

The following categories of evidence-based medicinal and nonmedicinal treatment are available (see Figure 3 for treatment algorithm):

- Proton pump inhibitors

- Helicobacter pylori eradication treatment

- Phytotherapy

- Antidepressants

- Psychotherapy.

\section{Acid-suppressing medications}

Numerous multinational randomized controlled trials of proton pump inhibitors (PPI) have demonstrated a significant favorable effect against functional dyspepsia compared with placebo (35). One meta-analysis showed a 10 to $20 \%$ higher treatment effect for PPI than for placebo (RRR 10.3\%; 95\% confidence interval $[2.7 ; 17.3]$ ) with a number needed to treat (NNT) of 14.7 patients (35). In subgroup analysis the PPI effects are limited to epigastric pain syndrome (RRR $12.8 \%[1.8 ; 34.3])$ or dyspeptic symptoms with accompanying

reflux (RRR 19.7\% [1.8; 34.3]), while dysmotility symptoms in the sense of a postprandial dyspeptic syndrome do not respond to PPI (RRR 5.1\% [10.9; 18.7]), enabling a differential therapeutic approach $(1,28,35)$.

Despite the positive study data, the PPIs have not been approved for treatment of functional dyspepsia in Germany. In the context of the recent public discussion of the potential side effects of PPIs, it can be stated that when used according to the indications these drugs are very safe, particularly since they are not employed for long-term management of functional dyspepsia (36).

\section{Further general measures}

- Conflict resolution in the psychosocial domain

- Encouraging the patient to take responsibility

- Relaxation exercises

- Treatment alliance for long-term care

- Psychotherapeutic options

\section{FIGURE 3}

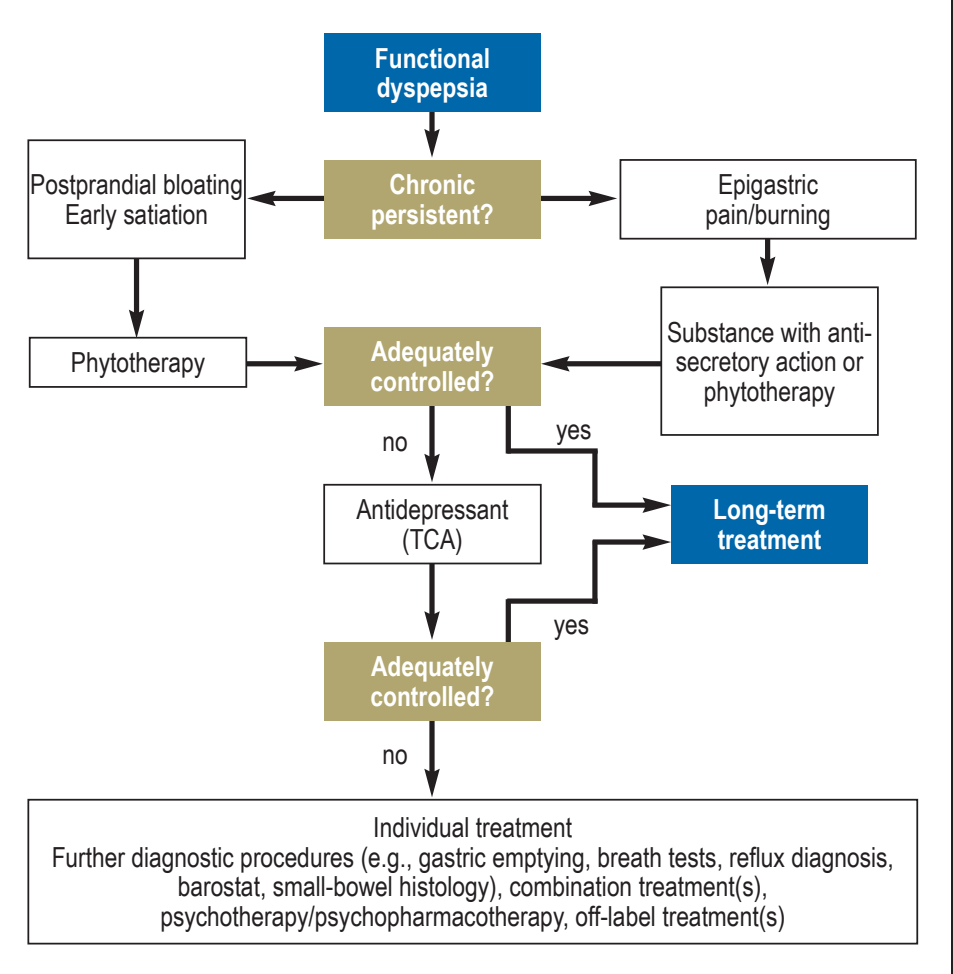

Treatment algorithm for dyspepsia, modified from (1)

\section{Eradication of Helicobacter pylori in functional dyspepsia}

The effect of $H$. pylori eradication treatment in functional dyspepsia has been the subject of a large number of placebo-controlled trials. Meta-analyses of all of these studies show a significant difference (OR 1.38 $[1.18 ; 1.62] ; \mathrm{p}<0.001)$ with a NNT of $15(33,37)$. After $H$. pylori eradication in $H$. pylori-positive functional dyspepsia, around $10 \%$ of patients stay symptom-free in the long term $(=H$. pylori-associated dyspepsia), while in the remaining patients the symptoms persist or return despite extirpation. It remains a topic of controversy in the literature whether $H$. pylori-associated dyspepsia is a subgroup of functional dyspepsia or represents an independent entity $(28,33)$.

However, this discussion is irrelevant in clinical practice. In view of the absence of causal treatments for functional dyspepsia, H. pylori eradication is an important treatment option because of its curative potential. For this reason it is recommended in German and international guidelines (38).

\section{Treatment options}

- Proton pump inhibitors

- Helicobacter pylori eradication treatment

- Phytotherapy

- Antidepressants

- Psychotherapy 


\section{Treatment options in functional dyspepsia}

\begin{tabular}{|c|c|c|}
\hline Medicinal treatment & Evidence level & Dosage \\
\hline Proton pump inhibitors ${ }^{* 1}$ & 1 & $\begin{array}{l}\text { Standard dosage of proton pump inhibitors }{ }^{* 2} \\
1 \times / \text { day }\end{array}$ \\
\hline $\begin{array}{l}\text { Phytotherapeutics } \\
\text { - STW } 5 \\
\text { - Menthacarin }\end{array}$ & $\begin{array}{l}1 \\
2\end{array}$ & $\begin{array}{l}3 \times 20 \text { drops } \\
2 \times 1 \text { capsule }\end{array}$ \\
\hline $\begin{array}{l}\text { Psychopharmaceuticals } \\
\text { - Amitryptiline }\end{array}$ & 2 & $25 \mathrm{mg} /$ day for 2 weeks, thereafter $50 \mathrm{mg} / \mathrm{day}$ \\
\hline Helicobacter pylori eradication treatment & 1 & According to the guideline on treatment of $\mathrm{H}$. pylori \\
\hline \multicolumn{3}{|l|}{ Nonmedicinal treatment } \\
\hline $\begin{array}{l}\text { Psychotherapy (e.g., cognitive behavioral therapy, } \\
\text { hypnosis) }\end{array}$ & 2 & - \\
\hline
\end{tabular}

${ }^{* 1}$ Not licensed for use in Germany

*2 Omeprazole $20 \mathrm{mg}$, pantoprazole $40 \mathrm{mg}$, rabeprazole $10 \mathrm{mg}$, esomeprazole $40 \mathrm{mg} 1 \times 1$, lansoprazole $15 \mathrm{mg}$

Evidence level 1, positive meta-analyses; evidence level 2, positive placebo-controlled studies

In the current guideline of the German Society for Gastroenterology, Digestive and Metabolic Diseases (Deutsche Gesellschaft für Gastroenterologie, Verdauungs- und Stoffwechselkrankheiten, DGVS) (33) H. pylori eradication is a "can" indication. The potential side effects of antibiotic treatment must always be taken into consideration in the course of decision making.

\section{Phytotherapy and complementary treatment options} Phytotherapeutics have long been used in medicine. Numerous placebo-controlled trials have shown a significantly positive effect of phytotherapy compared with placebo in the treatment of functional dyspepsia $(34, \mathrm{e} 1)$. Combined preparations are often used to treat functional dyspepsia. Mostly these are fixed combinations of peppermint and caraway oil or mixtures of bitter candytuft (Iberis amara), wormwood, gentian, and angelica root, usually in combination with spasmolytic and sedative extracts such as chamomile, peppermint, caraway, and lemon balm. Phytotherapeutics exert a spasmolytic tonus-stimulating and/or sedative effect on the gastrointestinal tract and this may relieve the symptoms of functional dyspepsia (34). In Germany the commercial preparations STW $5(39, \mathrm{e} 1)$ and Menthacarin (e2) are routinely used, on the basis of evidence of their effect. Preclinical data have now demonstrated the mechanisms of action of phytotherapeutics in the gastrointestinal tract and shown that the multitarget approach of using combinations of several different extracts has an additive and synergistic effect (40). In a meta-analysis of three placebocontrolled trials, treatment with STW 5 for 4 weeks was significantly superior to placebo (OR 0.22 [0.11;0.47]; $\mathrm{p}=0.001$ ) (39). A subsequent larger multicenter placebo-controlled trial over a period of 8 weeks confirmed the treatment effect (e3). In the wake of numerous positive placebo-controlled studies, phytotherapy is now recommended in German and international guidelines for use against functional gastrointestinal disorders, in particular functional dyspepsia and IBS $(1,6)$. Treatment of functional dyspepsia with digestive enzymes has also been studied, whereby the clinical action of the fixed combinations of gastric mucosal extract and amino acid hydrochlorides that are used is exerted not via substitution but by supporting the proteolytic release of amino acids. A randomized, placebo-controlled, double-blind crossover trial with 1167 patients (e4) showed a significant effect of this treatment in reducing the individual symptoms of dyspepsia $(p<0.001)$, but further preclinical and clinical studies are required for confirmation. Other complementary treatments such as acupuncture have yielded heterogenous effects in controlled trials and are therefore not recommended for functional dyspepsia (5, 13). There is also no evidence so far for the efficacy of homeopathy or probiotics.

\section{Antidepressants and psychotherapy}

Antidepressants are used after failure of the abovementioned treatments. Efficacy has been confirmed for

\section{Eradication of Helicobacter pylori}

In view of the absence of causal treatments for functional dyspepsia, $H$. pylori eradication is an important treatment option because of its curative potential. For this reason it is recommended in German and international guidelines.

\section{Phytotherapy}

Phytotherapeutic preparations are mostly fixed combinations of peppermint and caraway oil or mixtures of bitter candytuft (Iberis amara), wormwood, gentian, and angelica root, usually in combination with spasmolytic and sedative extracts such as chamomile, peppermint, caraway, and lemon balm. 
tricyclic antidepressants but not for serotonin reuptake inhibitors (e5). The largest study to date investigated the effect of amitryptiline ( $25 \mathrm{mg}$ for 2 weeks, then $50 \mathrm{mg}$ for 10 weeks), escitalopram (10 mg for 12 weeks), and placebo in a total of 292 patients. While escitalopram showed no effect, amitryptiline reduced the burden of the predominant symptom, abdominal pain, significantly compared with placebo (OR 3.1 $[1.1 ; 9.0])(\mathrm{e} 6)$. Other studies have also shown that antidepressants are particularly effective against dyspepsia symptoms when the predominant complaints are abdominal and/or mental comorbidity (e5). There are also data supporting the use of psychotherapy, which should be considered particularly in the case of treatment resistance $(13, \mathrm{e} 7)$.

\section{Prokinetics}

Because motility disorders are a possible underlying cause of functional dyspepsia, prokinetics can be considered for treatment. A meta-analysis of 14 studies demonstrated that prokinetics were more effective than placebo $(5,10)$. Cisapride and domperidone were the substances mostly studied. Cisapride was withdrawn from the market some time ago owing to cardiotoxicity, while the adverse effects of domperidone and metoclopramide mean that their use is restricted, particularly in long-term treatment. Thus, there are currently no prokinetics that can be used in daily clinical practice. The selective $5-\mathrm{HT}_{4}$ agonist prucalopride is effective against functional dyspepsia when the indication for treatment is refractory obstipation, but no controlled trials have been performed so prucalopride has not been licensed. Aciotamide (a muscarinic autoreceptor inhibitor and cholinesterase inhibitor), itopride, and levosulpiride (both selective dopamine- $\mathrm{D}_{2}$ antagonists) are further prokinetically active pharmaceuticals that have proven effective in controlled studies but have not yet been approved for use in Germany (e8-e10).

\section{Conclusion and algorithm for treatment of dyspepsia}

Primary-care physicians are initially confronted with uninvestigated dyspepsia, which must not be confounded with functional dyspepsia. "Uninvestigated" means that no diagnostic assessment, in particular no instrumental examinations, has yet been carried out to exclude organic causes. The following three strategies for diagnosis and treatment of uninvestigated dyspepsia can be distinguished (Figure 2) $(28,34)$ :

\section{Antidepressants}

Antidepressants are used after failure of the above-mentioned treatments. Efficacy has been confirmed for tricyclic antidepressants but not for serotonin reuptake inhibitors.

- Observation ("watchful waiting")

- Empirical treatment

- Primary diagnostic work-up including laboratory tests, esophagogastroduodenoscopy, and abdominal ultrasonography, followed by specific treatment according to the findings.

The observational strategy without any medicinal intervention is usually not practicable, because most patients present at a time when their symptoms are pronounced and demand help as quickly as possible.

By empirical treatment we mean medication with one of the groups of substances named above. The choice of substance depends on the predominant symptom. Randomized trials from English-speaking countries have shown that primary endoscopy is superior to empirical treatment, because an absence of abnormality on endoscopy leads to greater patient satisfaction and a considerable proportion of patients who start on empirical treatment eventually have to be examined by endoscopy $(9,34)$.

Functional dyspepsia with the cardinal symptom of upper abdominal pain can initially be treated with a PPI, followed by phytotherapy if there is no response. If symptoms of dysmotility predominate, however, treatment should begin with phytotherapy. Should an accompanying $H$. pylori infection be found, German guidelines recommend treatment to eradicate $H$. pylo$r i$. In refractory cases, following screening for anxiety, depression, and stress, antidepressants and psychotherapeutic interventions can be considered.

\section{Conflict of interest statement}

Prof. Madisch has received consultancy fees from Nordmark, Bayer Vital, and Dr. Willmar Schwabe; payments for acting as reviewer from Bayer Vital; and reimbursement of travel and accommodation costs as well as payments for training courses from Nordmark, Bayer Vital, and Dr. Willmar Schwabe.

Dr. Andresen has received consultancy fees from Shire and Nordmark.

Prof. Labenz has received consultancy fees from Nordmark and Dr. Willmar Schwabe and reimbursement of travel and accommodation costs as well as payments for training courses from Dr. Willmar Schwabe.

Prof. Schemann has received funds from Steigerwald for a research project of his own initiation.

Prof. Enck and Prof. Frieling declare that no conflict of interest exists.

Manuscript received on 4 July 2017, revised version accepted on 21 February 2018

Translated from the original German by David Roseveare

\section{Psychotherapy}

There are also data supporting the use of psychotherapy, which should be considered particularly in the case of treatment resistance. 


\section{Further information on CME}

- Participation in certified continuing medical education is possible only via the Internet: cme.aerzteblatt.de. This unit can be accessed until 24 June 2018. Submissions by mail, e-mail, or fax cannot be considered.

- The following CME units can still be accessed:

- "Diabetes in Childhood and Adolescence"

(issue 9/2018) until 27 May 2018

- "Osteoporotic Pelvic Fractures" (issue 5/2018) until 29 April 2018

- "Current Approaches to Epistaxis Treatment in Primary and Secondary Care" (issue 1-2/2018) until 2 April 2018

- This article has been certified by the North Rhine Academy for Postgraduate and Continuing Medical Education. The acquired CME points can be managed with the 15-digit uniform CME number (Einheitliche Fortbildungsnummer, EFN). The EFN must be entered in the appropriate field in the cme.aerzteblatt.de website under "Meine Daten" ("my data"), or upon registration. The EFN appears on each participant's CME certificate.

\section{References}

1. Stanghellini V, Talley NJ, Chan F, et al.: Rome IV - Gastroduodenal Disorders. Gastroenterology 2016 pii: S0016-5085(16)00177-3.

2. Ford AC, Marwaha A, Lim A, Moayyedi P: What is the prevalence of clinically significant endoscopic findings in subjects with dyspepsia? Systematic review and meta-analysis. Clin Gastroenterol Hepatol 2010; 8: 830-7.

3. Madisch A, Hotz J: Gesundheitsökonomische Aspekte der funktionellen Dyspepsie und des Reizdarmsyndroms. Gesundh ökon Qual manag 2000; 5: 32-5.

4. Moayyedi PM, Lacy BE, Andrews CN, Enns RA, Howden CW, Vakil N: ACG and CAG. Clinical Guideline: Management of dyspepsia. Am J Gastroenterol 2017; 112: 988-1013.

5. Talley NJ, Ford AC. Functional dyspepsia. N Engl J Med 2015; 373: 1853-63.

6. Talley NJ, Walker MM, Holtmann G: Functional dyspepsia. Curr Opin Gastroenterol 2016; 32: 467-73.

7. GFK Marktforschung Nürnberg: Die 100 wichtigsten Krankheiten. Woran die Deutschen nach Selbsteinschätzung leiden. ApothekenUmschau 1/2006.

8. Eggleston A, Farup C, Meier R: The domestic/international gastroenterology surveillance study (DIGEST): design, subjects and methods. Scand J Gastroenterol 1999; 231(Suppl): 9-14.

9. Lacy BE, Weiser KT, Kennedy AT, Crowel MD, Talley NJ: Functional dyspepsia: the economic impact to patients. Aliment Pharmacol Ther 2011; 33: 561-71.

10. Talley NJ: Functional dyspepsia: Advances in diagnosis and therapy. Gut and Liver 2017; 3: 349-57.

11. Oustamanolakis, $P$, Tack J: Dyspepsia: organic versus functional. J Clin Gastroenterol 2012; 46, 175-90.

12. Schemann M: Reizdarm und Reizmagen-Pathopysiologie und Biomarker. Gastroenterologe 2017; 2: 114-29.

13. Enck P, Azpiroz F, Boeckxstaens G, et al.: Functional dyspepsia. Nat Rev Dis Primers 2017; 3: 17081.

14. Bortolotti M, Bolondi L, Santi V, Sarti P, Brunelli F, Barbara L: Patterns of gastric emptying in dysmotility-like dyspepsia. Scand J Gastroenterol 1995; 30, 408-10.

15. Kim DY, Delgado-Aros S, Camilleri M, et al.: Noninvasive measurement of gastric accommodation in patients with idiopathic nonulcer dyspepsia. Am J Gastroenterol 2001; 96: 3099-105.

16. Coffin B, Azpiroz F, Guarner F, Malagelada JR: Selective gastric hypersensitivity and reflex hyporeactivity in functional dyspepsia. Gastroenterol 1994; 107, 1345-51.
17. Troncon LE, Thompson DG, Ahluwalia, NK, Barlow J, Heggie L: Relations between upper abdominal symptoms and gastric distension abnormalities in dysmotility like functional dyspepsia and after vagotomy. Gut 1995; 37: 17-22.

18. Mertz H, Fullerton S, Naliboff B, Mayer EA: Symptoms and visceral perception in severe functional and organic dyspepsia. Gut 1998; 42 , 814-22.

19. Simrén M, Törnblom H, Palsson OS, et al.: Visceral hypersensitivity is associated with GI symptom severity in functional GI disorders: consistent findings from five different patient cohorts. Gut 2018; 67 255-62.

20. Mearin F, Cucala M, Azpiroz F, Malagelada JR: The origin of symptoms on the brain-gut axis in functional dyspepsia. Gastroenterol 1991; 101: 999-1006.

21. Grundy D, Al-Chaer ED, Aziz Q, et al.: Fundamentals of neurogastroenterology: basic science. Gastroenterol 2006; 130: 1391-411.

22. Bouin M, Lupien F, Riberdy-Poitras M, Poitras P: Tolerance to gastric distension in patients with functional dyspepsia: modulation by a cholinergic and nitrergic method. Eur J Gastroenterol Hepatol 2006; 18: 63-8.

23. Lee KJ, Demarchi B, Demedts I, Sifrim D, Raeymaekers P, Tack J.A Pilot study on duodenal acid exposure and its relationship to symptoms in functional dyspepsia with prominent nausea. Am J Gastroenterol 2004; 99: 1765-73.

24. Samsom M, Verhagen MA, vanBerge Henegouwen GP, Smout AJ: Abnormal clearance of exogenous acid and increased acid sensitivity of the proximal duodenum in dyspeptic patients. Gastroenterol 1999; 116: $515-20$.

25. Hammer J, Führer M, Pipal L, Matiasek J: Hypersensitivity for capsaicin in patients with functional dyspepsia. Neurogastroenterol Motil 2008; 20: 125-33.

26. Feinle-Bisset C: Upper gastrointestinal sensitivity to meal-related signals in adult humans - relevance to appetite regulation and gut symptoms in health, obesity and functional dyspepsia. Physiol Behav 2016; 62: 69-82.

27. Enck $P, A z i z Q$, Barbara $G$, et al.: Irritable bowel syndrome. Nat Rev Dis Primers. 2016; 2: 16014

28. Delaney B, Ford AC, Forman D, Moayyedi P, Qume M: Initial management strategies for dyspepsia. Cochrane Database Syst Rev 2005; 19; CD00196.

29. Labenz J, Koop H. [Gastro-oesophageal reflux disease - how to manage if PPI are not sufficiently effective, not tolerated, or not wished?]. Dtsch Med Wochenschr 2017; 142: 356-66.

30. Van Oudenhove L, Aziz Q: The role of psychosocial factors and psychiatric disorders in functional dyspepsia. Nat Rev Gastroenterol Hepatol 2013; 10: 158-67.

31. Oudenhove L, Walker MM, Holtmann G, Koloski NA, Talley NJ: Mood and anxiety disorders precede development of functional gastrointestinal disorders in patients but not in the population. Clin Gastroenterol Hepatol 2017; 15: 1014-20.

32. Pinto-Sanchez MI, Ford AC, Avila CA, et al.: Anxiety and depression increase in a stepwise manner in parallel with multiple FGIDs and symptom severity and frequency. Am J Gastroenterol 2015; 110: 1038-48.

33. Fischbach $W$, Malfertheiner $P$, Lynen Jansen $P$, et al.: S2k-Leitlinie Helicobacter pylori und gastroduodenale Ulkuskrankheit. Z Gastroenterol 2016; 54: 327-63.

34. Madisch A, Miehlke S, Labenz J: Management of functional dyspepsia: Unsolved problems and new perspectives. World J Gastroenterol 2005; 11: 6577-81.

35. Wang WH, Huang JQ, Zheng GF, et al.: Effects of proton-pump inhibitors on functional dyspepsia: a meta-analysis of randomized placebo-controlled trials. Clin Gastroenterol Hepatol. 2007; 5: 178-85.

36. Mössner J: The indications, applications, and risks of proton pump inhibitors. Dtsch Arztebl Int 2016; 113: 477-83.

37. Zhao B, Zhao J, Cheng WF, et al.: Efficacy of Helicobacter pylori eradication therapy on functional dyspepsia: a meta-analysis of randomized controlled studies with 12-month follow-up. J Clin Gastroenterol 2014; 48: 241-7. 
38. Sugano K, Tack J, Kuipers EJ, et al.: Kyoto global consensus report on Helicobacter pylori gastritis. Gut 2015; 64: 1353-67.

39. Melzer J, Rosch W, Reichling J, Brignoli R, Saller R: Meta-analysis: phytotherapy of functional dyspepsia with the herbal drug preparation STW 5. Aliment Pharmacol Ther 2004; 20: 1279-87.

40. Hohenester B, Rühl A, Kelber O, Schemann M: The herbal preparation STW5 has potent and region-specific effects on gastric motility. Neurogastroenterol Motil 2004; 16: 765-73.

\section{Corresponding author}

Prof. Dr. med. Ahmed Madisch

Gastroenterologie, Interventionelle Endoskopie, Diabetologie, Akutgeriatrie

Klinikum Region Hannover GmbH, Klinikum Siloah

Stadionbrücke 4, 30459 Hannover, Germany

ahmed.madisch@krh.eu

Supplementary materia

For eReferences please refer to:

www.aerzteblatt-international.de/ref1318

\section{-O CLINICAL SNAPSHOT}

\section{Skin Changes Revealing a Disorder of Lipid Metabolism}

A 30-year-old man complained of a progressively severe, itchy rash of several weeks' duration. He reported suffering from polydipsia and hyperhidrosis but felt otherwise well. Examination of the skin revealed generalized orange-yellow, flat, hard papules, partly in mulberry-like clusters, most prominently affecting the extensor surfaces of the limbs and gluteal region. His past medical history and drug history were unremarkable except for obesity. Laboratory tests revealed hypertriglyceridemia (6470 mg/dL [70-200]), hypercholesterolemia (748 mg/dL [140-240]), and hyperglycemia (glucose $404 \mathrm{mg} /$ $\mathrm{dL}$ [70-110], HbA1c 11.2\% [<5.7]), without any evidence of an occult adrenal tumor. The diagnosis of eruptive xanthomas was histopathologically confirmed. The patient was treated for newly diagnosed diabetes mellitus and mixed hyperlipoproteinemia, and the rash regressed within weeks. Eruptive xanthomata are associated with dyslipidemia and can there-

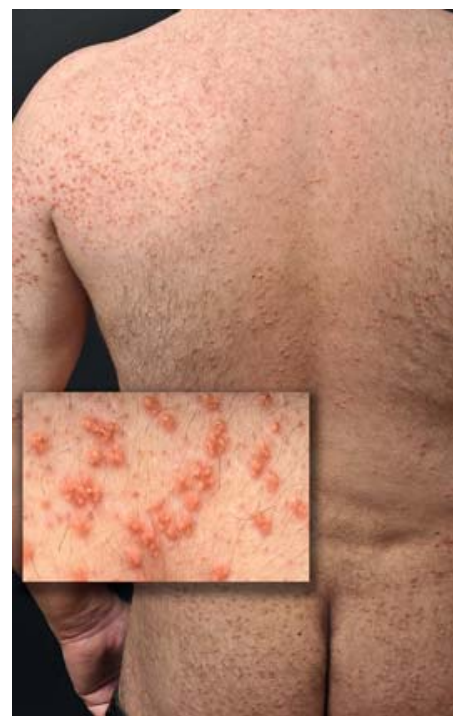

Disseminated, generalized, orange-yellow, flat, hard papules (detail), partly in mulberry-like clusters, affecting limbs and body

fore be a marker of a metabolic disorder. By recognizing their typical appearance, a physician may be able to diagnose a previously occult underlying disease whose prompt treatment can prevent both short-term complications, such as pancreatitis, and long-term ones, such as coronary heart disease.

Dr. med. Andreas Benedikt Weins, Prof. Dr. med. Tilo Biedermann, Prof. Dr. med. Knut Brockow, Klinikum rechts der Isar, Technische Universität München, Klinik und Poliklinik für Dermatologie und Allergologie am Biederstein, andreas.weins@mri.tum.de

\section{Conflict of interest statement}

The authors declare that no conflict of interest exists.

\section{Cite this as:}

Weins AB, Biedermann T, Brockow K: Skin changes revealing a disorder of lipid metabolism. Dtsch Arztebl Int 2018;

115:231. DOl: 10.3238/arztebl.2018.0231

Translated from the original German by Ethan Taub, M.D. 


\section{Participation in CME via cme.aerzteblatt.de. This unit can be accessed until 24 June 2018.}

Only one answer is possible per question. Please select the most appropriate answer.

\section{Question 1}

Which of the following procedures is crucial for the diagnosis of functional dyspepsia?
a) 24-h esophageal $\mathrm{pH}$ monitoring
b) Esophagogastroduodenoscopy
c) $\mathrm{H}_{2}$ breath test with lactose
d) Manometry
e) Bronchoscopy

Question 6

For which of the following is there evidence of efficacy in the treatment of functional dyspepsia?
a) Probiotics
b) Homeopathy
c) Acupuncture
d) Stool transplantation
e) Phytotherapy

\section{Question 2}

What proportion of Germans complain of bloating, flatulence, heartburn, and diarrhea?
a) 8 to $10 \%$
b) 18 to $20 \%$
c) 22 to $30 \%$
d) 32 to $40 \%$
e) 42 to $50 \%$

\section{Question 7}

The presence of which of the following in the duodenum can trigger the symptoms of functional dyspepsia?
a) Fat
b) Monosaccharides
c) Disaccharides
d) Wholemeal products
e) Animal proteins

\section{Question 3}

Which of the following symptoms counts as epigastric pain?
a) Stomach cramps
b) Bloating
c) Retching
d) Loss of appetite
e) Nausea

Question 8

Which of the following diseases shows considerable overlap with functional dyspepsia?
a) Irritable bowel syndrome
b) Sphincter of Oddi dysfunction
c) Achalasia
d) Schatzki ring
e) Nutcracker esophagus

\section{Question 4}

Which of the following is typical for functional

dyspepsia?
a) Short history
b) Weight loss
c) Symptoms mainly at night
d) Heartburn
e) Alternating periods of severe and mild symptoms

\section{Question 5}

Which of the following is essential when commencing the treatment of a patient with functional dyspepsia?
a) Explanation of the diagnosis and treatment options
b) Initiation of psychotherapy
c) A low-carbohydrate diet
d) Referral for colonoscopy
e) Small-intestinal biopsy

Question 9

Which of the following terms is often incorrectly used as a synonym for functional dyspepsia in Germany?
a) Gastritis
b) Peritonitis
c) Endometriosis
d) Ulcerative colitis
e) Crohn disease

Question 10

Which of the following criteria must be met for functional dyspepsia to be diagnosed?

a) Colonization with Helicobacter pylori

b) Demonstration of diverticulitis

c) No demonstration of an organic cause on endoscopy

d) Demonstration of granulomas in the small intestine

e) Edema of the intestinal mucosa 
Supplementary material to:

\section{The Diagnosis and Treatment of Functional Dyspepsia}

by Ahmed Madisch, Viola Andresen, Paul Enck, Joachim Labenz, Thomas Frieling, and Michael Schemann

Dtsch Arztebl Int 2018; 115: 222-32. DOI: 10.3238/arztebl.2018.0222

\section{eReferences}

e1. Madisch A, Vinson BR, Abdel-Aziz H, et al.: Modulation of gastrointestinal motility beyond metoclopramide and domperidone: Pharmacological and clinical evidence for phytotherapy in functional gastrointestinal disorders. Wien Med Wochenschr 2017; 167: 160-8.

e2. Madisch A, Heydenreich CJ, Wieland V et al.:Treatment of functional dyspepsia with a fixed peppermint oil and caraway oil combination preparation as compared to cisapride. A multicenter, reference-controlled double-blind equivalence study. Drug Res 1999; 49 (II): 925-32.

e3. von Arnim U, Peitz U, Vinson B, Gundermann KJ, Malfertheiner P: STW 5, a phytopharmacon for patients with functional dyspepsia: results of a multicenter, placebo-controlled double-blind study. Am J Gastroenterol 2007; 102: 1268-7.

e4. Brilmayer H, Faust W, Schliemann J: Non-ulcer dyspepsia. Beschwerden und deren medikamentöse Beeinflussung. in: Maiwald et al., Periodica Medica: Enzynorm forte - funktionelle Bedeutung und klinische Wirksamkeit. Reinbek: Einhorn Presse Verlag, 1988:71-85.

e5. Ford AC, Luthra P, Tack J, et al.: Efficacy of psychotropic drugs in functional dyspepsia: systematic review and meta-analysis. Gut 2017; 66: 410-420.

e6. Talley NJ, Locke GR, Saito YA, et al.: Effect of amitriptyline and escitalopram on functional dyspepsia: A multicenter, randomized controlled study. Gastroenterology 2015; 149: 340-9.

e7. Orive M, Barrio I, Orive VM, et al.: A randomized controlled trial of a 10 week group psychotherapeutic treatment added to standard medical treatment in patients with functional dyspepsia. J Psychosom Res 2015; 78: 563.

e8. Mearin F, Rodrigo L, Pérez-Mota A, et al.: Levosulpiride and cisapride in the treatment of dysmotility-like functional dyspepsia: a randomized, double-masked trial. Clin Gastroenterol Hepatol 2004; 2: $301-8$.

e9. Xiao G, Xie X, Fan J, et al.: Efficacy and safety of acotiamide for the treatment of functional dyspepsia: systematic review and metaanalysis. Scientific World Journal 2014: 541950.

e10. Holtmann G, Talley NJ, Liebregts T, Adam B, Parow C: A placebocontrolled trial of itopride in functional dyspepsia. N Engl J Med 2006; 354: 832-40. 